This is a preprint of a chapter accepted for publication by Facet Publishing. This extract has been taken from the author's original manuscript and has not been edited. The definitive version of this piece may be found in Developing Digital Scholarship: Emerging practices in academic libraries Facet, London. 9781783301102 which can be purchased from http://www.facetpublishing.co.uk/title.php?id=301102\#.WBkv29we3oV The author agrees not to update the preprint or replace it with the published version of the chapter. Our titles have wide appeal across the UK and internationally and we are keen to see our authors content translated into foreign languages and welcome requests from publishers. World rights for translation are available for many of our titles. To date our books have been translated into over 25 languages.

\title{
Developing Digital Scholars: From the ivory tower to the Twittersphere Alison Hicks
}

\section{Introduction}

Who or what is a digital scholar? Questions such as this are often surprisingly absent from librarian literature, either being sidelined in our rush to establish a digital scholarship centre or neglected in our push to capitalise upon interest in open access (OA) publishing and, more recently, open educational resources (OER). Yet, while the establishment of physical and financial backing for these efforts is vitally important, our disregard for the underlying (and occasionally contentious) scholarly practices and activities that support these goals is troublesome. Just as we saw with Web 2.0 hype back in the early 2000s, a focus on the shiny new technologies rather than on the practices and individual capacities needed to engage within these new environments runs the risk of reducing digital scholarship to a technical or instrumental skillset and neglecting the broader sociocultural issues that are at play within this arena, including questions about the nature and purpose of scholarship in an era of increased accountability, impact and control. The focus on the tools rather than the people also constitute a missed opportunity for librarians.

This chapter will explore our changing understandings of digital and open scholarship as well as the librarian's role in supporting the development of the capacities that are needed to engage within these environments. Defining a digital scholar as "someone who employs digital, networked and open approaches to demonstrate specialism in a field" (Weller, 2011, 5), and digital scholarship as comprising three major forms: open education, open access and networked participation (Veletsianos \& Kimmons, 2012a, 168), the chapter will be split into three sections. The first section will start by exploring the concept of digital scholarship, drawing out the connections between digital, networked, participatory and open scholarship. The chapter will then focus more concretely on the idea of networked participation, or the use of online social networks to "share, reflect upon, critique, improve, validate, and... develop... scholarship" (Veletsianos \& Kimmons, 2012a, 168), paying particular attention to how changing ideas of academic influence, reputation and identity intersect with the realities of contemporary academia. Finally, the third section of the chapter will use a series of practical examples to explore how librarians can use these ideas to facilitate researcher learning and development as well as further discussion in the field.

\section{What is digital scholarship?}

In some respects, it is no wonder that the term "digital scholarship" has been so confused in recent years- whether a researcher limits themselves to the use of word processing software and the library's online catalog or engages daily in large scale, data intensive collaborative research, there 
can be few scholars nowadays who fail to use technology when they engage in scholarly practices. In this vein, the concept of digital scholarship may seem tautological, at best. However, when these same activities are seen through the lens of research that has explored the tangled nature of digital scholarship, it becomes obvious that the picture is not so clear cut. The meaning of scholarship, for example, is complex, being defined in 1990 by Ernest Boyer in terms of discovery, integration, application and teaching rather than just as the generation of new knowledge. Viewed in this light, digital scholarship must be understood as going beyond the adoption of new research methods to engage more deeply with personal habits as well as ideas of outreach, engagement and education.

The definition of digitality is equally complicated. While the term could refer to the use of new technologies to enhance research, for example, making scholarship faster or more collaborative, (Veletsianos \& Kimmons, 2012b, 767), it is clear that the social and networked affordances of new technologies open up a number of different opportunities within the field. Social media, for example, helps scholars to share their research, for example through blogging or social network sites such as Twitter. However, while the ability to make connections and communicate is useful, it is the value of openness as well as the concepts of participation and informal collaboration that are inherent within this act of sharing that can be seen as more remarkable. These ideas mean that, in effect, it is an embracing of the "open values, ideology and potential of technologies born of peer-to-peer networking and wiki ways of working in order to benefit both the academy and society," or the affordances rather than the use of these technologies (Pearce, Weller, Scanlon \& Kinsley, 2011) that can be seen as constituting the focus on the digital within this definition. This has a number of repercussions for our understanding of digital scholarship.

One of the most important consequences centres on the nature of digital scholarship. As Veletsianos and Kimmons point out, the practices that are invoked as scholars use these new technologies in their research suggest that rather than replicating or merely amplifying old scholarly norms, digital scholarship has the potential to enhance or to transform its very shape and structure (2012b, 768). In other words, digital scholarship cannot be characterised by the translation of old norms (such as publishing models) into new technological infraestructures. Instead, as Greenhow and Gleason highlight, digital scholarship "leverage[s] social media affordances (ie, promotion of users, their inter-connections and user-generated content) and potential values (ie, knowledge as decentralized, co-constructed, accessible and connective) to evolve the ways in which scholarship is accomplished in academia" $(2014,3)$. These practices transform both the reach and the meaning of scholarship. A secondary consequence relates to the development of digital scholars; the evolution of new forms of scholarly communication, outputs and networks (Weller, 2011) means that digital scholarship cannot just be limited to functional skill-based literacy. Instead, as communities negotiate and work to integrate these new values into shared meaning making and understandings, teaching and learning must centre on the development of dynamic capacities or the ability to act and make decisions within these environments rather than on fixed sets of skills.

Emerging from social constructivist understandings of knowledge that position the development of meaning as decentralised, accessible and socially mediated, digital scholarship can thereby be linked to the goal of encouraging more inclusive research as well as reacting against "the hierarchies and elitism of traditional academia, with its gatekeepers and its exclusionary literacy practices and strategies of preferment" (Goodfellow, 2014, 2). These ideas have lead Veletsianos and Kimmons to characterise digital scholarship as being enacted through three major forms: open access and open publishing; open education, including open educational resources and open teaching; and networked participation (2012a). While open access and open educational resources 
need no introduction for librarians, it is the idea of networked participation, or "scholars' use of participatory technologies and online social networks to share, reflect upon, critique, improve, validate, and further their scholarship" (Veletsianos \& Kimmons, 2012b, 768) that remains less well known in the field, despite the direct relevance to many aspects of librarian practice. Centred upon the idea that scholars now have the capacity to "collaborate, build academic community, solicit feedback, and develop public relevance for their work" through digital networks (Glass, 2015, 2), it is clear that the openness engendered within these practices could serve as both a source of opportunity as well as a point of tension as academics adjust and adapt to the changing realities of higher education. The chapter will now turn to exploring these ideas in more detail.

\section{Networked Participation: Opportunity and Tension}

Centring on a number of emergent practices, networked participation has generally referred to the use of technologies such as video-sharing sites, blogging and micro-blogging tools as well as social media services in order to communicate, discuss, publish and reflect on ideas in an open, public space (Greenhow \& Gleason, 2014, 3). This means that a scholar who has uploaded a manuscript for feedback to Academia.edu can be seen to be sharing ideas with broader audiences before formal publication, or an educator who is using Twitter to engage in professional or social commentary with others in the field, and a PhD student who is using a Wordpress blog to discuss emerging ideas from her thesis can be said to be engaging in networked participatory scholarship. Structured around research development and bringing in connectivist ideas of learning as network building (Siemens, 2005), these practices seem particularly worthy, being grounded in a push to democratise education and scholarship.

Yet, despite the admirable educational aims, it is clear that these ideas about research activity often exist in a certain state of tension. Digital scholarship does not exist in a vacuum and this vision of networked participation could be seen as somewhat idealised. Or, as Goodfellow (2014) so astutely puts it: do the ideas of open, scholarly and digital form an impossible triangle? Scholars work in a "context of relatively conservative value and reward systems that have the practice of peer review at their core" (Harley, Krzys Acord, Earl-Novell, Lawrence \& King, 2010, 13), a system that has been built on notions of exclusivity as well as the premise of knowledge scarcity rather than abundance (Stewart, 2015). They also tend to be employed in a system that, increasingly, links the value of education to economic productivity, and measures academic achievement and output in similar terms of quality assessment (Greenhow \& Gleason, 2014, 2). Viewed in this light, it is apparent that the idea of networked participatory scholarship, with its focus on openness and sharing, can be seen as neither straightforward nor as unproblematic. It also raises a number of important questions about the essence of scholarly work within these new realities, as well as the concept of a digital scholar and the nature of the very technologies themselves.

One of the most commonly cited tensions regarding networked participation centres on the positioning and the impact of these scholarly practices within "'entrenched' academic reward and promotion structures" (Veletsianos, 2013, 642). In other words, while new, participatory practices may reach new communities or have created new forms of peer evaluation, academia does not currently have a way of measuring or valuing this impact and engagement. In fact, blogging work may still be considered secondary for many administrations, even while it is used as the basis for published, or peer-reviewed work (Skallerup Besette, 2015). Coupled with reports that bloggers have occasionally either been treated with "disdain" during promotion and tenure reviews (Lupton, 2014, 4) or have felt like they were jeopardising future job prospects (Lupton, 2014, 24), these ideas mean 
that scholars may consider that they need to refrain from publishing work openly (Goodfellow, 2014, 7), or, at the very least, engage more discretely online. The experiences of Steven Salaita, a professor whose appointment from the University of Illinois was rescinded for comments made from his personal Twitter account, form a case in point (Stoytcheva, 2015). In effect, academics are often using these new technologies to build influence and reputation, or in very similar ways to traditional academic purposes, for instance to build influence and reputation. However, because these interactions look very different within new, participatory networks (that are built upon and emphasise open sharing and collaboration), academia does not yet have a way to recognise or value contributions (Stewart, 2015, 18).

The emphasis on influence also highlights another area of growing interest and concern; what do these new developments mean for the digital scholar's identity? Engagement on social media requires that academics value "transparency and responsiveness, a willingness to work in public and to help others feel comfortable doing the same" as well as multi-platform, multi-identity academic selves (Utell, 2015). Yet, the fact that social networks were originally designed and employed for the maintenance of personal relationships raises a number of questions about boundaries between both personal and professional identities, as well as the need to negotiate these practices when the technology is often expressly designed to discourage these competing identifications (Lupton, 2014, 6). This lack of privacy has further lead many academics to question whether their academic identities may be "undermined" by their forays into networked participation, with several of Lupton's research participants wondering about the credibility or the perceived quality of their online work $(2014,22)$. Similarly, it is clear that for academics who identify with a minority gender, sexual, racial or ethnic identity, the risks of participating online or the costs of the emotional labour may not outweigh the benefits, with scholars expressing concern about misogynistic (Mitchell, 2013) or racial (Cottom McMillan, 2012) online harassment, amongst other issues. These aggressions are compounded by the existence of easily accessible internet archives.

Lastly, it is clear that the very tools that we use for participatory scholarship cannot be considered as neutral platforms from which we can engage in networked practices. For some, technologies reinforce existing structures rather than open up social norms, with personalising algorithms within social media services (Bucher, 2012) or search engines (Umoja Noble, 2012) leading to filter bubbles of like-minded individuals, or relevant information (Pariser, 2011). For others, the instability of digital publications and networks makes them, ironically, less accessible to a global readership (Goodfellow, 2013). In addition, the for-profit or venture capitalist funding that is behind common social media or repository sites such as academia.edu and Facebook, means that many are starting to question and draw attention to these sites' commitment to the open values of networked participation, their appearance of educational status notwithstanding (Fitzpatrick, 2015). Even Wikipedia, whose values of collaborative accessibility often position it as the poster child of the networked participation movement, can be critiqued for its limited representation of certain countries, communities and their knowledges (Graham, Hogan, Straumann \& Medhat, 2014) as well as for its inherent gender bias (Wagner, Garcia, Jadidi \& Strohmaier, 2015). Bias is not limited to tools, either. The methods chosen to research the current state of networked participation may exclude a number of participants (Fransman, 2013) with Veletsianos and Kimmons (2012b) warning that future research may find that the ideals of educational justice that are assumed to drive networked participatory scholarship may, in fact, be characteristics of early adopters rather than intrinsic to these practices. 
In sum, there are a number of admirable aims within emerging scholarly practices. Notwithstanding, the issues highlighted here demonstrate the importance of taking a critical approach to the use and development of new technologies and practices. While this may seem overly negative, it is clear that an uncritically positive depiction of new tools and devices can lead to the problematic narratives of technology's revolutionary, disruptive or "emancipatory" potential within education that are currently seen in both academic and popular writing (Hall, 2011; Veletsianos, 2013). A critical gaze can help draw attention to these issues and, as educators who are actively immersed in today's information landscapes, librarians are perfectly placed to lead and contribute meaningfully to these conversations.

\section{Librarian roles}

Librarian involvement within questions of digital scholarship can take a number of forms and formats but generally tends to centre on the role of a repository manager or a scholarly communication librarian. In focusing on the idea of networked participation, however, this chapter argues that digital scholarship is also an area of interest for instruction librarians, dovetailing neatly with existing researcher education initiatives. As a consequence, this chapter will highlight a number of instructional outreach and engagement activities that centre on these ideas of digital scholarship and networked participation. Unlike traditional library trainings, though, which may tend to centre on a specific tool, for example EndNote or Impact Story, the focus within this section will be on education related to the practices, or the explicit and implicit activities that afford digital scholarship. This approach is far less common within librarianship, yet, as Veletsianos and Kimmons (2012a) point out, scholars need to be able to "develop an understanding of the affordances of the participatory web for scholarship and consider the implications of online identity and digital participation" or the literacies that are needed to engage with these networks, rather than just the technical expertise. At the same time, these practices should not be taught as if they were a fixed or a limited skillset. Instead, they should be seen as dynamic, flexible and subject to change, as communities engage with both the possibilities and the pitfalls of networked participation. Illustrative examples of these ideas will be drawn from work at the author's home institution, the University of Colorado, Boulder (UCB).

One way that librarians can integrate questions of digital scholarship into their teaching and researcher outreach initiatives and efforts is through re-centring existing workshops around the practices of networked participation rather than merely highlighting the software. In other words, rather than focusing on demo-ing the nuts and bolts of a useful tool, a session could be reimagined around an exploration of how this tool might fit into the researcher's existing individual and disciplinary or community based practices, as well as in conjunction with other technologies that they are using. These ideas are borne out by research demonstrating that rather than experiencing problems with the technical functionality of these tools, scholars often struggle with the integration of these tools into their existing workflow, or when they are faced with competing disciplinary demands and norms (Hicks \& Sinkinson, 2015). A recent study of the reference manager, Mendeley, for example, found that while researchers often wanted to use the social and networked capacity of Mendeley to share and work collaboratively, they were frequently hobbled by local norms for citation sharing and storage (that built upon email networks and existing libraries of references) as well as dominant disciplinary practices, for example preference for the use of a Facebook group for networking (Hicks \& Sinkinson, 2015). 
At UCB, these ideas have directly lead to the creation of workshops that focus on workflow and software feature comparison rather than on technical features. A reference manager workshop, for example, is now structured around a comparison of Mendeley, Zotero, Endnote and Papers, rather than immediately siphoning learners into learning one specific, or institutionally mandated technology. Most importantly, however, the workshop is centred on attendee needs, starting with a series of questions about participants' research and study practices, as well as their disciplinary norms or constraints rather than the software's features and affordances. Having sensitised workshop attendees to the importance of reflecting on their current habits and practices (including their preferred study location, as well as how they find, organise, read and share research materials), the workshop then highlights how each tool could match participant needs rather than vice versa. This simple switch has been welcomed by participants, with one attendee noting "it was very helpful to have a brief overview of each system, then an assessment to help me choose which one would work best for me, then more in depth information about the one I chose." Comments like this demonstrate how the workshop now helps learners to match their needs to a tool rather than vice versa, and make an informed decision about their research practice needs and development. These ideas can also be seen in Coonan's use of animal metaphors to explore reference management workflow and practice (2013).

Research into networked participation and digital scholarship has also lead to the creation of a series of new workshops at UCB. Focusing on complex questions about digital scholar practices within a networked world, these workshops have been explicitly developed to develop learner awareness and facility with a number of new scholarly practices such as the development of online identities, or the measurement and improvement of impact. Rather than listing potential sites for researcher profiles, however, these workshops are centred, as above, on researcher practices rather than on tools. They are further characterised by their emphasis on the pitfalls as well as on the opportunities of digital technologies, or the need to provide a critical appraisal of these tools. Thus, the Creating a digital identity workshop spends considerable time questioning the purpose and goals of an online identity, as well as discussing the benefits and drawbacks of using commercial sites for networking and as a research portfolio. Similarly, the workshop that focuses on Improving your impact critically engages with the concepts of outreach, public discourse and measurement, asking participants to reflect on the nature of 'impact' and the forces behind the sudden interest in this topic, as well as serving as a how-to primer about ways to open up and share personal and collaborative research practices.

Many participants mention that they find the focus on practical details useful, including scholar profiles, the measurement of impact, and advice about sharing research and teaching materials. Others find that this workshop forms a neutral space that can help uncover assumptions as well as legitimate fears and concerns among the participants. This often helps them to join the dots between scraps of information they have absorbed, for instance, between their knowledge that they can put published articles online and a vague understanding of the rules that govern this by developing specific knowledge about negotiating contracts, permission and institutional or commercial repository sites. Attendees also mention that the workshop forms a space to discuss and experiment with questions of digital identity in an open way, rather than solely relying on confused advice from a supervisor or dire warnings about the value of engaging on social media from a PhD committee member. We have found that many participants, for example, are urged to stay away from public engagement for fear of someone stealing either their ideas or their work. Others are cautioned against publishing open access because it may later harm their ability to negotiate a book 
contract. While these concerns are important, participants appreciate this workshop because it presents a rounded picture of both the benefits and the drawbacks of engaging online and enables individuals to make their own informed decision about their next academic steps. In turn, the open and questioning nature of workshops such as these have enabled librarians to become more sensitive to these issues and to temper their enthusiasm for online engagement and open access with a measured appraisal of the reality of academic pressures and disciplinary norms. This format has also helped to foreground the structural constraints that can affect the notion of success in the academy, or the idea that we cannot assume that the use of different technologies or metrics will automatically lead to greater representation or quality of opportunity within higher education. There are many factors that affect visibility and prestige in the academy and it is clear that the focus on unpacking these ideas contributes to both the honesty and to the success of this workshop.

Beyond workshops, librarians at UCB have also partnered with educational technology staff in order to create public digital scholarship discussion fora. These events, which are open to the entire campus, acknowledge that digital scholarship is still developing and that scholars and their communities may need to work through a number of complex questions related to identity, participation and impact. Academics Online week, which was held at UCB in 2014, is one such example of a public discussion event, where scholars and librarians came together to exchange ideas about the nature of digital scholarship, and its potential impact on their work. On one level, this event served as a dropintechnology testing zone, where librarians and faculty gave mini overviews of a number of digital scholarship tools in the field, including Impact Story, Mendeley, Twitter and more. This half of the event allowed faculty and librarians to sit down in a one-on-one setting and try out the tools, while also hearing about how local experts on campus used these tools in their daily, academic lives. On another level, this event also included severalopen discussions about the nature of digital scholarship and what this means to campus faculty, educational technology staff and librarians, including panels entitled "What is Open Scholarship" and "What is Open Access". These events facilitated a number of discussions and broader debate about the nature of openness and digitality. They also served to raise awareness about these issues on campus, further sparking a number of follow up workshops and consultations about questions of digital scholarship. We found that a discursive approach to changing academic realities was particularly helpful because it grounded practices within the messy everyday nature of digital scholarship, rather than presenting it in theoretical or ideal terms. This made the topic approachable to a wide variety of campus faculty and graduate students as well as serving to draw attention to the 'in-progress' nature of practices, and the need for further discussion and work in the area. Our emphasis on including a wide variety of interdisciplinary perspectives, or a mix of speakers from different disciplines also helped us to break this topic down for our campus; the variety of perspectives meant that discussion was lively and participants were able to make a number of useful comparisons and connections across scholarly traditions. In addition, and while this wasn't our original goal, we found that these events also served as a site of professional development for librarians, many of whom had started to receive questions about altmetrics or the legality of using academic social media sites, and wanted to improve their knowledge in the area.

Lastly, but most importantly, undergraduates, too, can be included in these conversations around digital scholarship. Open access is an obvious starting point with many universities now making undergraduate theses and senior projects available through institutional repositories. Undergraduate research is often seen as "immature and unpolished, drafts not-ready-forprimetime" as well as liable to undermine the faculty member's reputation (Miller, 2013). Yet, as 
Hicks and Howkins point out, "if we believe that undergraduate students have nothing to contribute to a particular field, it is worth asking ourselves what such an attitude communicates to students about the nature of the... discipline and their place within it" (2015, p. 355). Open access undergraduate publishing can thereby be seen as a way for students to exercise their academic agency by both entering into and participating within broader conversations around their interests. As libraries start to become more involved with digital publishing (Michigan Publishing, for example, forms a part of the University of Michigan Libraries), as well as scholarly communication and other initiatives that focus on broadening the reach and the visibility of Open Access publishing, it is clear that undergraduate research can play an important part within the library's goals of making information accessible for all (Miller, 2013). Beyond the technological implications for making undergraduate research available, the inherent focus on research accountability reinforces everyday meanings of information literacy (Booth \& Miller, 2014) and instruction sessions may need to take a different shape when undergraduate research form part of scholarly conversations. Librarians involved in information literacy instruction can help to scaffold undergraduate student researcher needs by focusing on information privilege, or the need for open access publishing, as well as paying greater attention to attribution, copyright and permissions (Booth, 2013).

The concept of networked participation also forms a useful way to think about redesigning undergraduate research assignments, which, like in traditional academic reward systems, tend to focus exclusively on the final essay, or the product of research. In our role as subject specialists and liaisons, a number of scholars and practitioners have started conversations with interested faculty about the nature of research assignments, and ways in which we can break or slow down the research process (Blackwell-Starnes, 2011; Deitering \& Gronemyer, 2011; Sinkinson \& Hicks, 2013; Mihailidis \& Cohen, 2013; Hicks \& Howkins, 2015),). By working with faculty to redesign assignments around the intermediary academic practices that may eventually lead to a final paper (for example, by following a Twitter hashtag, or mapping a scholar's informal online conversations), we make questions of inquiry, as well as authority and evaluation more visible to students, as well as scaffolding their participation in and exploration of today's complex information landscapes. And, while this idea is not yet scalable, it is clear that the process of working with faculty as co-designers of educational experiences has also lead to a number of benefits, including a greater understanding of each other's role, and a more relevant and responsive research assignment. Students react well to these new ideas, too, with one student in the Hicks and Howkins study pointing out that "having been forced to look at largely primary sources, make inferences, and draw conclusions to connect dots that haven't necessarily been connected before was a very different kind of experience (but a good one)" (2013, p.353). While this study found that students may initially be cautious at the idea of analyzing contemporary media such as blogs and tweets in a history class, it was clear that by the end of the class, students were engaging in far more sophisticated evaluation of the information environments that surround them.

\section{Conclusion}

Digital scholarship, and the idea of the digital scholar, form complex concepts that are constantly in flux as academic and scholarly researchers react to, make sense and create new disciplinary norms related to teaching, scholarship and individual research practices. In recent studies, digital scholarship has thereby referred to a number of related ideas, including:

1. building a digital collection of information for further study and analysis,

2. creating appropriate tools for collection building, 
3. creating appropriate tools for the analysis and study of collections,

4. using digital collections and analytical tools to generate new intellectual products, and

5. creating authoring tools for these new intellectual products, either in traditional form or in digital form (American Council of Learned Societies Commission on Cyberinfrastructure for the Humanities \& Social Sciences, n.d.)

This chapter argues, however, that it is the change in the scholarly practices around these tools and collections that is both noteworthy as well as a neglected opportunity for librarians. In other words, by seeing digital scholarship as constituting and being constitutive of a number of new, scholarly activities that are centred on principles of openness or social and networked participation, rather than just as the use of new technologies, we open up the potential for more meaningful and necessary conversation about the changing nature of academia. This approach also dovetails nicely with the recent drive (Accardi, Drabinski \& Kumbier, 2010) to broaden the way that we think of information literacy; as Crissinger points out, "asking faculty and graduate students to think critically about how we evaluate scholarship and what impact really means to them as scholars and information consumers is information literacy" (2015). These ideas can also be seen through the work of JISC in the UK, which has carried out significant research into digital capabilities, and includes digital communication and collaboration as well as traditional information literacy skills as a key part of a researcher's digital capacity. In effect, these ideas illustrate both the dynamic nature and the critical need for information literacy within today's complex information landscapes.

At the same time, it is clear that communities who explore both the role and the place of these new practices may not always recognise or even share the open ideals from which the concept of networked participation was born. Just as MOOCs were transformed from their radically open, connectivist beginnings into more traditional models of online education, digital scholarship runs the risk of becoming distanced from ideas of openness and failing to transform inherited scholarly practices. For some, interest in alternative systems of measurement has neglected to broaden the idea of research impact, continuing to treat "knowledge diffusion as a 'black box' with only inputs and outputs" or removing the concept of meaning from questions of public value (Budz Pedersen, 2015). For others, the focus on impact, for example in the Research Excellence Framework, which is a programme that assesses the research of British higher education institutions, has been critiqued for over-simplifying or marginalising the value and worth of non-immediately popular research (Mulholland, 2015). While it may be frustrating to see how easily goals of openness can be subverted, these issues could also be seen as demonstrating the emerging nature of the field, as well as highlighting the pressures that scholars and institutions face in an era of increased accountability. More positively, developments could also be seen as helping to create impetus for continued engagement; as open scholar, Bonnie Stewart points out, "we are part of a flawed system and open research is an important approach to solve it" (Notsosternlib, 2015). It is in this spirit that librarians should approach digital scholarship, drawing upon our core professional values to continue advocating for the creation of academic practices that are as open, as accessible and as diverse as we can possibly make them.

\section{References}

Accardi, M. T., Drabinski, E., \& Kumbier, A. (2010). Critical library instruction: Theories and methods. Duluth, Minn: Library Juice Press.

American Council of Learned Societies Commission on Cyberinfrastructure for the Humanities \& 
Social Sciences (n.d.). What is Digital Scholarship? Open Stax.

http://cnx.org/contents/3e6519f7-9f9a-4060-a5af-567a8e959f2c@1/What-Is-DigitalScholarship

Blackwell-Starnes, A. 2011. Academic research, professional discourse: Social bookmarking as a catalyst for rhetorical research pedagogies. PhD Thesis, Texas Woman's University.

Booth, C. (2013). Open Access as Pedagogy. Info-mational. https://infomational.wordpress.com/2013/07/29/open-access-as-pedagogy/

Booth, C. \& Miller, C. (2014). Open Access as Undergraduate Pedagogy. Library Journal. http://lj.libraryjournal.com/2014/03/opinion/backtalk/open-access-as-undergraduatepedagogy-backtalk/\#_

Boyer, E. L. (1990). Scholarship reconsidered: Priorities of the professoriate. Princeton, N.J: Carnegie Foundation for the Advancement of Teaching.

Bucher, T. (2012). Want to be on the top? Algorithmic power and the threat of invisibility on Facebook. New Media \& Society 14(7), 1164-1180.

Budz Pedersen, D. (2015). Real impact is about influence, meaning and value: Mapping contributions for a new impact agenda in the humanities. The Impact Blog. http://blogs.Ise.ac.uk/impactofsocialsciences/2015/07/27/mapping-the-public-influence-of-t he-humanities/

Coonan, E. (2013). Referencing without tears. Research Skills Central. https://researchcentral.wordpress.com/2013/11/13/referencing/

Cottom McMillan, T. (2012) Risk and ethics in public scholarship. University of Venus, https://www.insidehighered.com/blogs/university-venus/risk-and-ethics-public-scholarship

Crissinger, S. (2015). The best work I do is at intersections. ACRLog. http://acrlog.org/2015/12/07/intersections/

Deitering, A. M., \& Gronemyer, K. 2011. Beyond peer-reviewed articles: using blogs to enrich students' understanding of scholarly work. portal: Libraries and the Academy, 11(1), pp.489503.

Fitzpatrick, K. (2015). Academia, not edu. Planned Obsolescence, http://www.plannedobsolescence.net/academia-not-edu/

Fransman, J. (2013) Researching academic literacy practices around Twitter: performative methods and their onto-ethical implications. In, Goodfellow, R., \& Lea, M. (eds) Literacy in the Digital University: Critical Perspectives on Learning, Scholarship and Technology, Routledge, London, 27-41.

Glass, E. (2015). Social Paper: Retooling Student Consciousness. Scholarly and Research Communication, 6(4).

Goodfellow, R. (2013) The literacies of digital scholarship- truth and use values. In, Goodfellow, R., \& Lea, M. (eds) Literacy in the Digital University: Critical Perspectives on Learning, Scholarship and Technology, Routledge, London, pp. 67-78.

Goodfellow, R. (2014). Scholarly, digital, open: an impossible triangle? Research in Learning Technology, 21.

Graham, M., Hogan, B., Straumann, R. \& Medhat, A. (2014). Uneven Geographies of User-Generated Information : Patterns of Increasing Informational Poverty Uneven Geographies of Knowledge. Annals of the Association of American Geographers 104(4), 746-764.

Greenhow, C., \& Gleason, B. (2014). Social scholarship: Reconsidering scholarly practices in the age of social media. British Journal of Educational Technology, 45(3), 392-402. 
Hall, R. (2011). Revealing the transformatory moment of learning technology: the place of critical social theory. Research in Learning Technology, 19(3), 273-284

Harley, D., Krysz Acord, S., Earl-Novell, S., Lawrence, S, \& Judson King, C. (2010). Assessing the future landscape of scholarly communication: An exploration of faculty values and needs in seven disciplines. Center for Studies in Higher Education, UC Berkeley.

Hicks, A., \& Howkins, A. (2015). Tipping the Iceberg: A Collaborative Approach to Redesigning the Undergraduate Research Assignment in an Antarctic History Capstone Seminar. The History Teacher, 48(2), 339.

Hicks, A., \& Sinkinson, C. (2015). Examining Mendeley: Designing learning opportunities for digital scholarship. portal: Libraries and the Academy, 15(3), 531-549.

Lupton, D. (2014). 'Feeling better connected': academics' use of social media. Canberra: News \& Media Research Centre, University of Canberra.

Mihailidis, $\mathrm{P}$ and Cohen, J.N. 2013. Exploring Curation as a core competency in digital and media literacy education. Journal of Interactive Media in Education 1(2).

Miller, C. (2013). Riding the Wave : Open Access, Digital Publishing, and the Undergraduate Thesis. Presentation at USETDA 2013 Conference.

http://scholarship.claremont.edu/pomona_fac_pub/377/

Mitchell, A. (2013). Take back the net: Institutions must develop collective strategies to tackle online abuse aimed at female academics. LSE Impact of the Social Sciences.

http://blogs.Ise.ac.uk/impactofsocialsciences/2013/07/24/take-back-the-net-female-acade mics-online-abuse/

Mulholland, J. (2015). Academics: forget about public engagement, stay in your ivory towers. The Guardian Higher Education Network.

http://www.theguardian.com/higher-education-network/2015/dec/10/academics-forget-ab out-public-engagement-stay-in-your-ivory-towers

Notsosternlib (2015, Oct 8). We are part of a flawed system and open research is an important approach to solve it. [Twitter post]

https://twitter.com/notsosternlib/status/652097968317706243

Pariser, E. (2011). The filter bubble. New York, NY: Penguin Press.

Pearce, N., Weller, M., Scanlon, E., \& Kinsley, S. (2011). "Digital scholarship considered : how new technologies could transform academic work." in education, 16(1).

Siemens, G. (2005). Connectivism: a learning theory for the digital age. International Journal of Instructional Technology and Distance Learning, 2(10), 3-10.

Sinkinson, C. \& Hicks, A. (2013) Unraveling the research process: Social bookmarking and collaborative learning. In S. Pixy Ferris \& H. Wilder (Eds.), The Plugged-in Professor: Tips and techniques for teaching with social media. Oxford: Chandos.

Skallerup Besette, L. (2015). Social media, service and the perils of scholarly affect. Hybrid Pedagogy. http://www.hybridpedagogy.com/journal/social-media-service-and-the-perils-of-scholarly-a ffect/

Stewart, B. (2015). Open to influence: what counts as academic influence in scholarly networked Twitter participation. Learning, Media and Technology 40(3), 1-23.

Stoytcheva, S. (2015). Steven Salaita and the critical importance of context: contingency and the ALA code of ethics. Paper presented at the Canadian Association of Professional Academic Librarians (CAPAL).

Umoja Noble, S. (2012). Missed connections: What search engines say about women. Bitch 12(54), 
36-41.

Utell, J. (2015). Redefining Service for the Digital Academic: Scholarship, Social Media, and Silos. Hybrid Pedagogy.

http://www.hybridpedagogy.com/journal/redefining-service-for-the-digital-academic/

Veletsianos, G. (2013). Open practices and identity: Evidence from researchers and educators' social media participation. British Journal of Educational Technology, 44(4), 639-651.

Veletsianos, G., \& Kimmons, R. (2012a). Assumptions and challenges of open scholarship. The International Review of Research in Open and Distributed Learning, 13(4), 166-189.

Veletsianos, G., \& Kimmons, R. (2012b). Networked participatory scholarship: emergent techno-cultural pressures toward open and digital scholarship in online networks. Computers \& Education, 58(2), 766-774.

Wagner, C., Garcia, D., Jadidi, M., \& Strohmaier, M. (2015). It's a man's wikipedia? Assessing Gender Inequality in an Online Encyclopedia. Proceedings of The International AAAI Conference on Web and Social Media (ICWSM2015), Oxford, UK.

Weller, M. (2011). The digital scholar: how technology is transforming scholarly practice. London: Bloomsbury Academic. 